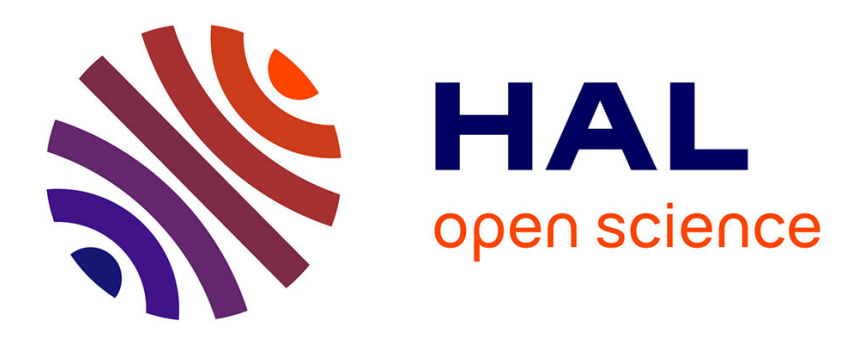

\title{
Publishing science without results and recycling research
}

Eric Lichtfouse

\section{To cite this version:}

Eric Lichtfouse. Publishing science without results and recycling research. Environmental Chemistry Letters, 2018, 16 (1), pp.1 - 4. 10.1007/s10311-017-0690-7 . hal-01711017

\section{HAL Id: hal-01711017 \\ https://hal.science/hal-01711017}

Submitted on 16 Feb 2018

HAL is a multi-disciplinary open access archive for the deposit and dissemination of scientific research documents, whether they are published or not. The documents may come from teaching and research institutions in France or abroad, or from public or private research centers.
L'archive ouverte pluridisciplinaire $\mathbf{H A L}$, est destinée au dépôt et à la diffusion de documents scientifiques de niveau recherche, publiés ou non, émanant des établissements d'enseignement et de recherche français ou étrangers, des laboratoires publics ou privés. 


\title{
Publishing science without results and recycling research
}

\author{
Eric Lichtfouse ${ }^{1}$
}

\begin{abstract}
Most scientists focus too much on publishing original articles. In doing so, scientists are restricting their writing skills to this form of highly specialised publication, which is poorly readable by scientists from other disciplines. In the context of rising interdisciplinary research and data abundance, there is a need for more publications that recycle existing research and communicate to a wider audience. Therefore, I present here five types of publications that do not require additional experiments, namely reviews, methods, data papers, meta-analyses and videos. Benefits include more citations, larger visibility, wider dissemination, easier job finding, grant success and better recycling of research.
\end{abstract}

Keywords Publication $\cdot$ Scientific writing $\cdot$ Review article $\cdot$ Methodological article $\cdot$ Protocol $\cdot$ Data paper $\cdot$ Meta-analysis $\cdot$ Video journal

\section{Introduction}

Most scientists focus too much on publishing original articles. Original articles, also called research articles, primary articles, results articles, reports, letters and communications, present the first results of research experiments. ${ }^{1}$ Publishing original papers is of course necessary for the advancement of science. Nonetheless, publishing solely original articles is not advised because original articles are highly specialised and thus readable by few experts only, but rarely by the average employer. Moreover, writing only original articles will restrict the authors writing skills to this specific format, and, in turn, the author will not develop skills to communicate to a wider audience. In other words, authors should favour publication diversity rather than quantity. This letter presents five types of publications that do not require additional experiments: reviews, methods, data papers, metaanalyses and videos (Fig. 1). Detailed writing advices are given in the book Scientific Writing for Impact Factor Journals, which includes a new tool to identify novel results, the Micro-Article. ${ }^{2}$

\section{Eric Lichtfouse}

Eric.Lichtfouse@inra.fr; Eric.Lichtfouse@gmail.com

https://www.linkedin.com/in/ericlichtfouse/

1 CEREGE, Aix-Marseille Univ, Coll de France, CNRS, INRA, IRD, Europôle Méditerranéen de l'Arbois, 13545 Aix en Provence, France

\section{Reviews}

Also termed review articles, literature reviews or systematic reviews, reviews summarise the current state of understanding on a topic. ${ }^{3}$ Book chapters are also often literature reviews in science. A review is a critical analysis of a substantial number of original articles, e.g. more than 50. Reviews thus reveal facts, results, methods, techniques and concepts that have been shown and reproduced by several scientists. Reviews are therefore an essential step in the advancement of science because reviews link research and education by making a synthesis of primary fi

Writing a review article requires three skills: mastering the search of online databases, the ability to read and evaluate critically the papers and to incorporate the selected readings into an integrated account. A fast method to write a review is described. ${ }^{4}$

In the context of the increasing pace of scientific discovery and topical specialisation, there is a need for more reviews to connect different disciplines and to reach the public. Reviews are very useful for anyone starting to explore a new topic because the reader will understand rapidly the

\footnotetext{
${ }^{1}$ Scientific journal. https://en.wikipedia.org/wiki/Scientific_journal.

${ }^{2}$ Lichtfouse E. (2013) Scientific Writing for Impact Factor Journals. Nova Publishers. 103 p. https:/www.novapublishers.com/catalog/ product_info.php?products_id=42211.

${ }^{3}$ Review article. https://en.wikipedia.org/wiki/Review_article.

${ }^{4}$ Lichtfouse E. (2015) Writing a review article in 7 steps. https:// fr.slideshare.net/lichtfouse/writea-review.
} 


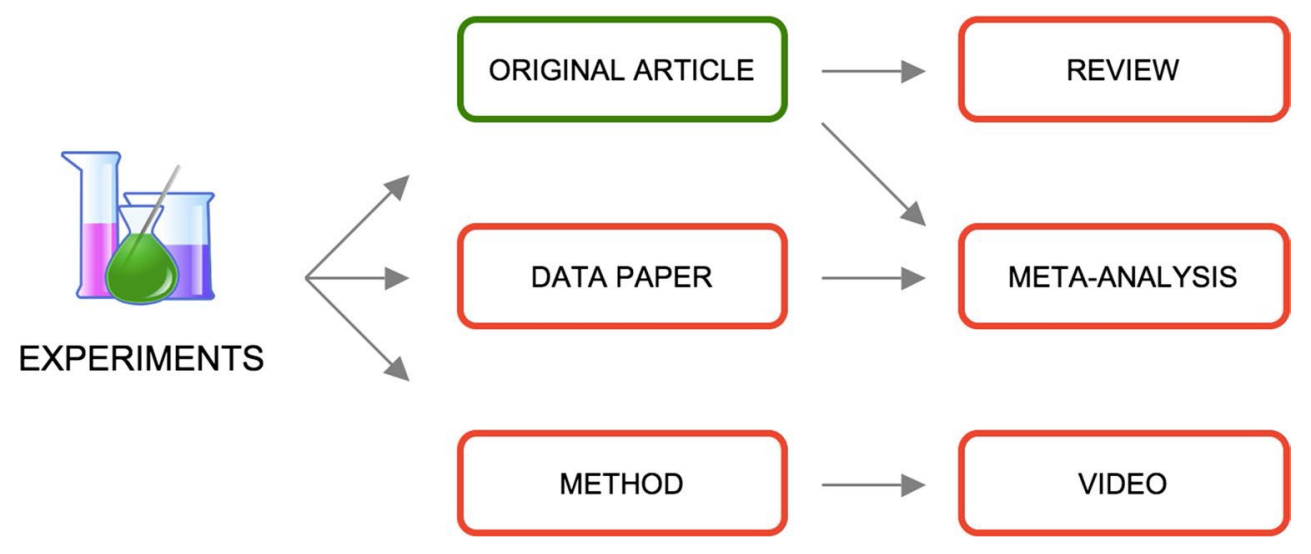

Fig. 1 Five scientific articles that can be published without results. Beside original articles that report the first research results, five types of manuscripts (red) do not need additional experiments: reviews analyse many recent articles to summarise the current state of knowledge on a topic. Data papers report datasets for further use, e.g. by other scientists. Meta-analyses are statistical analyses that combine the

last advances, thus saving time. Therefore, reading reviews is typically recommended to graduate students. Reviews are usually easier to read than original articles. As a consequence, employers, funding agencies and journalists will better understand a review than an original paper.

Reviews are often cited more than original articles because reviews reach a wider audience. More citations mean that journal editors will favour publication of review articles to increase the impact factor. ${ }^{5}$ As a result, the rejection rate of reviews is lower. Lastly, most Ph.D. theses do usually contain a chapter of literature review. So, publishing earlier this chapter as a review in a journal will be beneficial for the student, who will be transformed into a world expert of the analysed topic. I observed that Ph.D. students who published a review got a job shortly before or after their Ph.D. defence.

\section{Methods}

Also named methodological articles, protocols, procedures or techniques, methods papers describe new, modifi or improved research methods and techniques. ${ }^{6}$ Even if the initial research plan was to test a hypothetical concept, most scientists modify existing methods or invent new methods that fi better with their specifi experimental conditions. Those advanced methods are publishable. Most journals will favour publication of methods because methods are like cooking recipes; they are widely reproduced and, in turn,

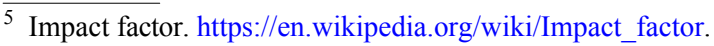

6 Scientific method. https://en.wikipedia.org/wiki/Scientific_method. Protocol. https://en.wikipedia.org/wiki/Protocol_(science).
}

results of multiple scientific studies to reveal a new trend or pattern. Methods describe advanced experimental methods, procedures and techniques. Videos provide fast and integrated information that cannot be conveniently described by text. Beaker photograph reprinted from David Vignoni at https://fr.wikipedia.org/wiki/Bécher

better cited. This citation advantage arises also from the fact that a single method fi applications in many diff ent disciplines, whereas an original article is often monodisciplinary. Many journals publish only methods articles, such as Springer Protocols, ${ }^{7}$ Nature Methods, ${ }^{8}$ Nature Protocols ${ }^{9}$ and Analytical Chemistry. ${ }^{10}$

\section{Data papers}

Data articles are manuscripts reporting datasets and complementary information allowing the data to be findable, accessible, understandable and interoperable, e.g. an abstract, a description of the method and metadata. ${ }^{11}$ Data are published in data journals, in data repositories or as supplementary material of an original article. Data papers often possess their own reference, e.g. a digital object identifi (DOI), allowing the dataset to be cited. This will increase the number of citations of the author. The actual rising number of data papers and data journals is explained by the fact that advanced research techniques produce too much data, most of them being not analysed nor interpreted. Publishing a data paper is therefore a means to decrease research waste by sharing and recycling unused data. Published data can be used to write a meta-analysis, for example. Data journals

\footnotetext{
7 Springer Protocols. http://www.springerprotocols.com.

${ }^{8}$ Nature Methods. http://www.nature.com/nmeth.

9 Nature Protocols. http://www.nature.com/nprot.

10 Analytical Chemistry. http://pubs.acs.org/journal/ancham.

11 Data publishing. https://en.wikipedia.org/wiki/Data_publishing.
} 
include Scientific Data ${ }^{12}$ and Data in Brief. ${ }^{13}$ Dryad $^{14}$ is an example of data repository. ${ }^{15}$

\section{Meta-analyses}

A meta-analysis is a statistical analysis that combines the results of multiple scientific studies to reveal a new trend or pattern. ${ }^{16,17}$ A key benefit of meta-analyses is the aggregation of data from many investigations, leading to a higher statistical power, and thus a conclusion more robust than is possible from the measure derived from any individual study. A meta-analysis is therefore an article type intermediary between a review and an original article. It is indeed a review of already published data, and it reveals an original result. There are very few journals publishing solely metaanalyses, but most journals accept meta-analyses because such papers usually disclose outstanding discoveries of global reach and, in turn, are well cited.

\section{Videos}

Video papers often combine an online video demonstration of a new technique or protocol combined with a textual description, for instance the Journal of Visualized Experiments $^{18}$ (JoVE). This form of publication will gain more importance due to the easiness of designing and publishing videos in the digital age. In terms of communication, videos are more attractive than text and still fi es because the human eye is better attracted by motion. Videos are thus easier to view for scientists, the public and employers. In terms of scientific content, videos reveal in a short time many scientific informations that were very difficult or even impossible to explain in a text, for instance the detailed motion of the hand of scientist pouring drops of a toxic liquid using a Pasteur pipette.

\footnotetext{
$\overline{12}$ Scientific data. https://www.nature.com/sdata.

13 Data in Brief. https://www.journals.elsevier.com/data-in-brief.

14 Dryad. http://datadryad.org.

15 Recommended data repositories. https://www.nature.com/sdata/ policies/repositories.

${ }^{16}$ Meta-analysis. https://en.wikipedia.org/wiki/Meta-analysis.

${ }^{17}$ Haidich A.B. Meta-analysis in medical research. Hyppokratia 14 (Suppl 1): 29-37. https://www.ncbi.nlm.nih.gov/pmc/articles/PMC3 049418.

18 Journal of Visualised Experiments. https://www.jove.com.
}

\section{About the Author}

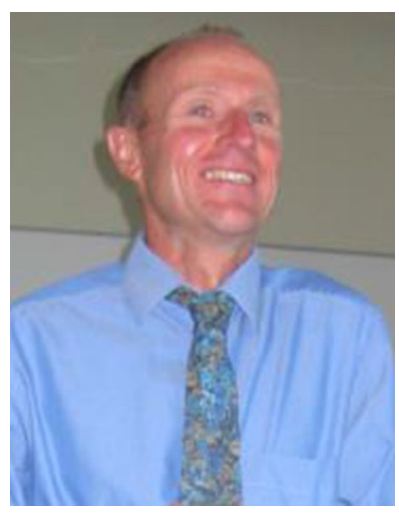

Eric Lichtfouse, born in 1960, is a biogeochemist studying carbon sequestration in soils in the context of climate change, at the Centre Européen de Recherche et d'Enseignement des Géosciences de l'Environnement (CEREGE), in Aix-enProvence, France. He has invented the ${ }^{13} \mathrm{C}$-dating method that allows to measure the dynamics of soil carbon at the molecular level. ${ }^{19} \mathrm{He}$ has published 60 articles and edited 30 books in chemistry, geochemistry, agronomy and soil science. ${ }^{20} \mathrm{He}$ is teaching scientific writing and communication and has published the book Scientifi Writing for Impact Factor Journals (See footnote 2). He is Editor-in-Chief and co-founder of Environmental Chemistry Letters ${ }^{21}$ Environmental Chemistry for a Sustainable World, ${ }^{22}$ Sustainable Agriculture Reviews ${ }^{23}$ and Publier La Science. ${ }^{24}$ His former journal Agronomy for Sustainable Development ${ }^{25}$ has been awarded the highest citation increase in Agricultural Sciences by the Essential Science Indicators in 2010. ${ }^{26}$

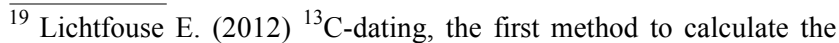
relative age of molecular substance homologues in soil. Environ. Chem. Lett. 10: 97-103. https://doi.org/10.1007/s10311-011-0334-2.

${ }^{20}$ Lichtfouse E. ResearcherID. http://www.researcherid.com/rid/F4759-2011. Google scholar. https://scholar.google.fr/citations?user $=$ MOKMNegAAAAJ

${ }^{21}$ Environmental Chemistry Letters. https://link.springer.com/jour nal/10311.

${ }^{22}$ Environmental Chemistry for a Sustainable World. http://www.spri nger.com/series/11480.

23 Sustainable Agriculture Reviews. http://www.springer.com/seri es/ $/ 8380$.

${ }^{24}$ Publier La Science. http://www6.inra.fr/caps-publierlascience.

${ }^{25}$ Agronomy for Sustainable Development. https://link.springer.com/ journal/13593.

${ }^{26}$ The success of Agronomy for Sustainable Development. http:// archive.sciencewatch.com/inter/jou/2010/10novAgrSusDev.
} 
The impact factor of this journal has increased from 0.6 in 2006 to 4.1 in 2016. The impact factor of Environmental Chemistry Letters has increased from 0.8 in 2006 to 3.6 in 2016. This journal is now placed in the first quartile of the category Environmental Sciences with a rank of 50 over 229 journals.
Acknowledgements I thank very much Prof. Dr. Jan Schwarzbauer, RWTH Aachen University, for advices to improve this manuscript. 